\title{
PROOF-OF-CONCEPT TESTING OF FLUIDIZED-BED COPPER OXIDE PROCESS
}

\section{Contract DE-AC22-85PC81004}

\section{PHASE IV \\ Conceptual Design and Economic Evaluation}

Technical Progress Report No. IV-4

(October 1992 - March 1993)

\section{for}

U.S. Department of Energy

Pittsburgh Energy Technology Center Pittsburgh, Pennsylvania

by

\section{UOP}

25 E. Algonquin Road

Des Plaines, Ilinois

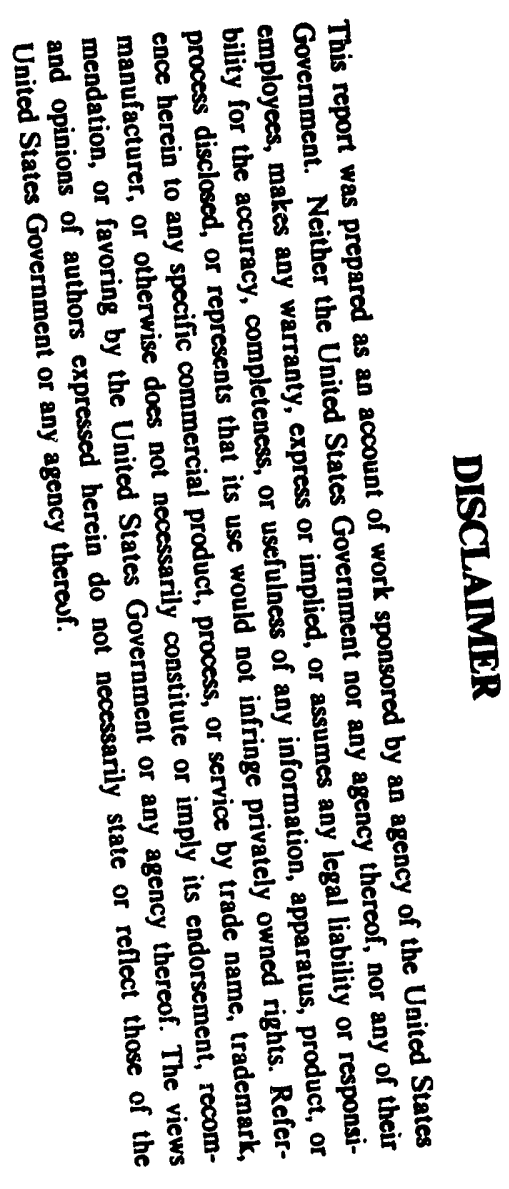

$\frac{8}{3}$

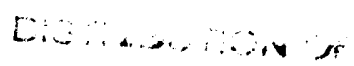

FATAT CHEARD EY CHICAGO

ope ois June 28 1993. 


\title{
PROOF-OF-CONCEPT TESTING OF \\ FiUUIDED-BED COPPER OXIDE PROCESS
}

Contract DE-AC22-85PC81004

HEP : $: 3$

PHASE IV

Conceptual Design and Economic Evaluation

$\operatorname{sep} 16: 3$

OOTI

Technical Progress Report No. IV-4

(October 1992 - March 1993)

\author{
H. B. Gala \\ UOP \\ 25 E. Algonquin Road \\ Des Phaines, nlinois
}

\section{CONTRACT OBIECTIVE}

The objective of Phase IV of the contract is to design a conceptual flue gas treating unit based on the fluidized-bed Copper Oxide (FBCO) process for a new coal-fired $500 \mathrm{MW}(e)$ power plant. A technical and economic evaluation of the FBCO process, based on the conceptual design, will also be completed.

\section{CONTRACT TASKS}

4.0 Proposal review and negotiations

4.1 Definition of design basis

4.1.1 Subcontractor negotiations

4.1.2 Design basis formulation

4.1.3 Design basis review and approval

4.2 500-MW(e) conceptual design

4.3 Economic Evaluation of the FBCO process

4.3.1 Technical and economic evaluation

4.3.2 Final report 


\section{SCOPE OF THE WORK DURING THE REPORTING PERIOD}

The scope of the work during this reporting period covered Tasks 4.2 and 4.3 of Phase IV of the contract. Work on Phase IV is being carried out by A. E. Roberts \& Associates, Inc. (AERA), UOP's subcontractor for Phase IV. AERA's Technical Progress Report for this period is attached to this report.

No progress has been made on DOE review of UOP's October 11, 1991, Technical and Cost Proposal for the Revised Phase IV under Task 4.0. UOP is waiting for a response from DOE. However, work on Phase IV has continued as directed by the change order, Modification M012 to the contract.

\section{FUTURE PLANS}

Work will proceed on completing Tasks 4.2 and 4.3 and preparing the Final Report for the contract. 


\section{A. E. ROBERTS \& ASSOCIATES, INC.}

May 17, 1993

Dr. Hemant B. Gala

UOP

25 East Algonquin Road

Des Plaines, Illinois 60017-5017

Our Ref: UOP-CON.071

Subject: Contract DE-AC22-85PC81004

Project Status Update (May 1993) for the Copper Oxide Process

\section{Dear Hemant:}

A.E. Roberts \& Associates, Inc. (AERA) has prepared a six month update letter report on the progress of the fluidized bed copper oxide flue gas treating process (CuO Process). To date, the activities mentioned herein have been completed except for the submittal of the Sensitivity Analysis. The first draft of the sensitivity analysis is expected to be completed during the third week of May 1993. During the last six months, six technical issues have been addressed by AERA:

- $\quad$ Re-evaluate the CuO Process at a 2.0:1 Cu:S molar ratio

- Size the Absorber and Regenerator for the CuO process at a Cu:S molar ratio of 2.0;

- Develop technical specifications for the absorber and regenerator;

- Develop technical specifications for the balance of plant.

- Preparation of Technical Papers: Conceptual Design for Eluidized Bed Copper Oxide Process for the Contractors review meeting in July 1993 and a paper prepared by Dr. Chris Frey: Performance Model of the Fluidized Bed Copper Oxide Process for $\mathrm{SO}_{2} / \mathrm{NO}_{x}$ Control, prepared for the 86th Annual Meeting for the Air and Waste Management Association;

- Preparation of the Technical and Cost Sensitivity Analysis for the CuO Process. 


\section{A. E. ROBERTS \& ASSOCIATES, INC.}

Dr. Hemant B. Gala

UOP

May 17, 1993

Page Two

The status and deliverables for each of these activities is discussed in the following sections.

\section{Revaluate the CuO Process at a 200100 Cuis Molar Ratio}

Based upon discussions with UOP and Carnegie Mellon University, AERA revised the material balance in the Establishment of the Desion Basis for Application to a $500 \mathrm{Mw}$ Power Plant report in January 1993. The material balance was revised to reflect a lower copper-to-sulfir molar ratio (2.0:1.0) for the design of the absorber and regenerator. The report was revised and resubmitied to UOP on January 12, 1993. A comparison of the revised material balance with Carnegie Computer Model indicated some minor discrepancies between the AERA material balance and the computer model. After reviewing the available data, it was concluded that slightly different assumptions were utilized and minor differences in empirical constants lead to the discrepancies between the balance and the model. AERA assumed that although both balances were developed correctly, the more conservative balance (higher material balance numbers) would be utilized in the sizing of the absorber and regenerator. The lower Cu:S (2.0:1.0) molar ratio versus the initial design molar ratio (3.0:1.0) also required that AERA reconsider the size of the dense phase transport system. Since the Cu:S molar ratio decreased, the dense phase transport system appeared to be adequaiely sized for the lower molar ratio.

Under this activity, in the future it may be necessary that AERA revise some sections of the material balance to insure that adequate engineering judgement has been utilized for sizing the absorber and regenerator. At this time, it is expected that some minor modifications to the balance may be required. A revised material balance reflecting the needs identified throughout the project will be prepared approximately two weeks after the completion of the sensitivity analysis. At this time it is expected the minor correction will not affect the size of the absorber or regenerator since in the sizing of the absorber and regenerator conservative engineering judgement was utilized.

\section{Sizing the Absorber and Regenerator for the CuO Process at a CuiS Molar Ratio of 20.10}

Once the material balance was revised, AERA sized the absorber and regenerator based upon the flue gas flow rate (752821 pounds per hour at 750F) and a Cu:S ratio of 2.0:1. Due to the potential size of a single train, i.e. absorber followed by a regenerator, a dual treatment train system was selected. The dual train system utilized two, two stage absorbers followed by a regenerator. Each absorber was sized based upon a 50 percent split of the 


\section{A. E. ROBERTS \& ASSOCIATES, INC.}

Dr. Hemant B. Gala

UOP

May 17, 1993

Page Three

flue gas flow rate after the boiler in the $500 \mathrm{Mw}$ conceptual design. In the conceptual design, after the flue gas is treated in the absorber, treated flue gas will be recombined after the regenerator. Based upon the conceptual design of the $500 \mathrm{Mw}$ unit, the dimensions of the absorber and regenerator are:

- Absorber

(2) Needed for Design

Diameter: 46.3 feet

Straight Wall Height: 108 feet
Regenerator

(2) Needed for Design

Diameter: 33.5 feet

Straight Wall Height: 104.6 feet

Schematics for the absorber and regenerator are provided in Attachment $\mathbf{A}$.

\section{Technical Specifications for the Absorber and Regenerator}

Once the sizing of the absorber and regenerator was completed, a general technical specification for each was prepared. The general technical specifications are intended to provide sufficient information to an equipment manufacturer to provide a capital cost estimate and develop potential structural requirements. Detailed specifications were not prepared since when preparing these types of specifications additional facility needs and system requirements need to be defined. The detailed needs of the absorber and regenerator may include: necessary structural requirements, installation procedures, additional instrumentation and reporting requirements, transportation requirements, etc. The specifications where prepared and drafts finalized during January and February 1993.

Once the general technical specifications were completed, draft copies were issued to equipment vendors to obtain approximate capital costs estimates. Due to the size of the equipment, some difficulty has been experienced in obtaining vendor cost estimates. The costs will also be utilized in cost comparisons developed during the sensitivity analysis. The costs represent a budget price for the erected equipment. 


\title{
A. E. ROBERTS \& ASSOCIATES, INC.
}

\author{
Dr. Hemant B. Gala \\ UOP \\ May 17, 1993 \\ Page Four
}

\section{Technical Papers}

Two technical papers were prepared during the past six months. One paper was prepared by Carnegie Mellon University (Performance Model of the Eluidized Bed Copper Oxide Process for $\mathrm{SO}_{2} / \mathrm{NO}_{2}$ Control) and another by AERA (Conceptuai Desion for Fluidized Bed Copper Oxide Process). The paper prepared by Carnegie Mellon University was for presentation at the 86th Annual Meeting of the Air and Waste Management Association. The paper prepared by AERA is for the contractors review meeting in July 1993 . As requested by UOP, AERA prepared a technical paper on the work AERA has been developing for UOP.

The Carnegie Mellon paper was developed to demonstrate the modeling of copper oxide process. The model was developed to predict the performance, emissions, and cost models for conventional and advanced technologies for pre-combustion, combustion, ard postcombustion environmental controls. Technical, chemistry, kinetic modeling and gereral process descriptions are presented in the technical paper. Limited costing information was provided in the technical paper.

The AERA paper was prepared to explain the CuO process and present technical issues which effect the potential use of the CuO process by industry. The AERA paper presented the general concept of the $\mathrm{CuO}$ process in addition to discussion of potential practical considerations when developing this process. The economic consideration for the absorber and regenerator were not discussed in the paper. Sorbent transportation system selection were also discussed as well as energy penalty and credits. AERA is currently preparing the presentation for the meeting which is to be held in July.

\section{Technical and Costs Sensitivity Analysis for the CuO Process}

The development of the technical costs and sensitivity analysis is ongoing. The sensitivity analysis report addresses three areas of the copper oxide process:

What the conceptual design of a full scale CuO process looks like;

- Technical requirements that need to be developed to support the full scale system; and 


\section{A. E. ROBERTS \& ASSOCIATES, INC.}

Dr. Hemant B. Gala

UOP

May 17, 1993

Page Five

- Competing flue gas clean-up technologies and their advantages, disadvantages and budgetary cost.

The overall goal of the sensitivity analysis is to provide a review of the technical and economic merit of the copper oxide process. The conventional flue gas cleaning technologies considered for sulfur and nitrous oxide cleaning in the analysis include:

- Limestone injection for sulfur dioxide control (either combustion or post combustion control);

- Ammonia injection for $\mathrm{NO}_{x}$ control;

- Urea injection for $\mathrm{NO}_{\mathrm{x}}$ control;

- Wet scrubbers;

- Selective Catalytic reduction; and

- Particulate removal technologies

The alternative flue gas clean-up technologies presented in the sensitivity analysis are conventionally available equipment. It is not the intent of the sensitivity analysis to identify every technology available, but to present some of the commercially available technologies.

Cost information for the sensitivity analysis are based upon cost estimates prepared by vendors, costing factors in guidance documents, and best available control technologies demonstration developed for coal fired facilities in the United States. The cost ranges presented in the sensitivity analysis are directly reflective of the amount of sulfur and 
Dr. Hemant B. Gala

UOP

May 17, 1993

Page Six

nitrogen removed. The estimated cost for the copper oxide process considers the total capital costs, annualized capital costs, capital expenses, operating and maintenance costs and energy costs. The annual operating and maintenance expenses were estimated at one percent of the installed equipinent cost. A siraft of the sensitivity analysis is anticipated to be prepared during the third week of May 1993.

Sincerely,

A. E. ROBERTS \& ASSOCIATES, INC.
A. E. Roberts

President

\section{AER:pan}

UOP-CON.071 

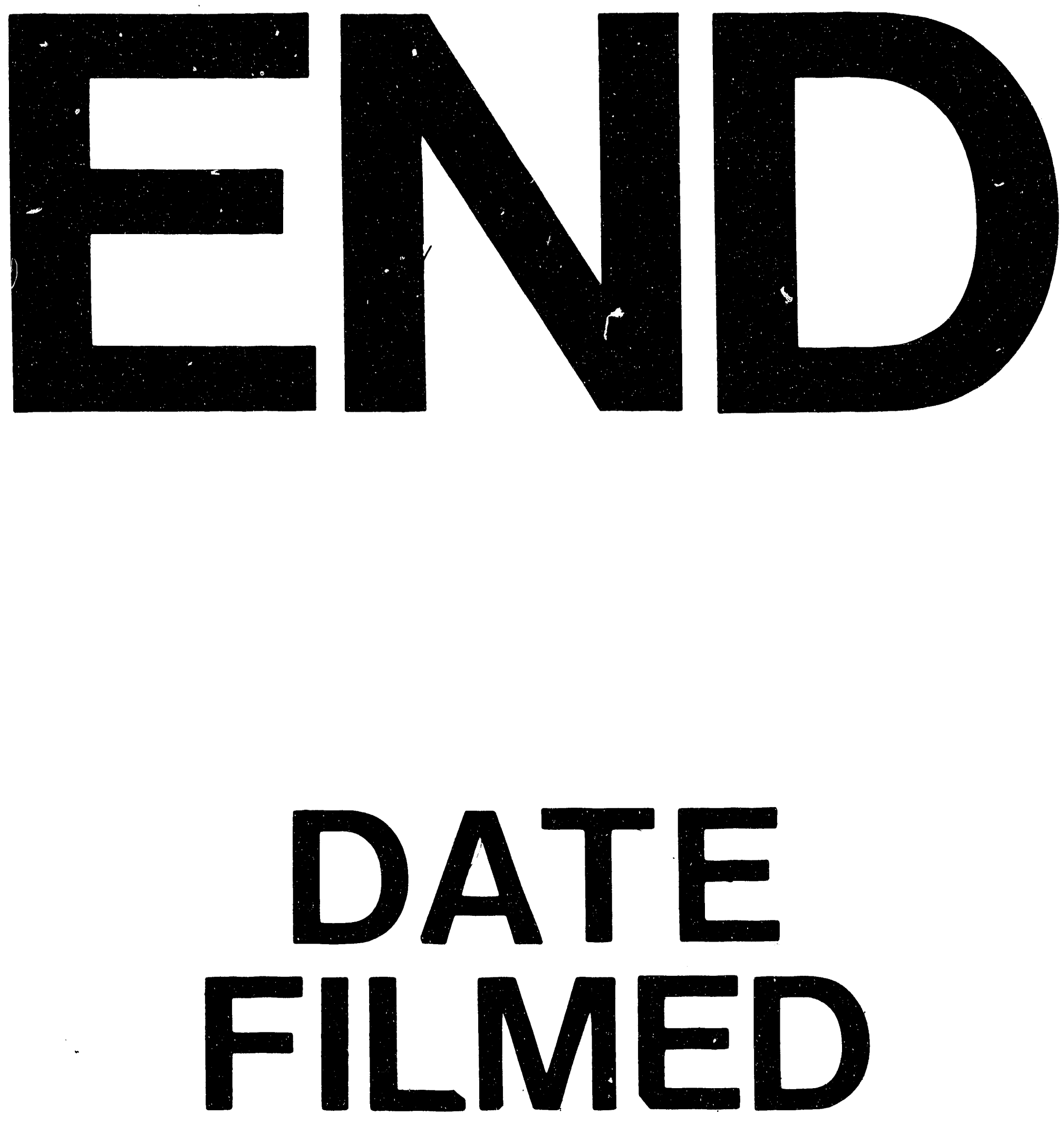

)

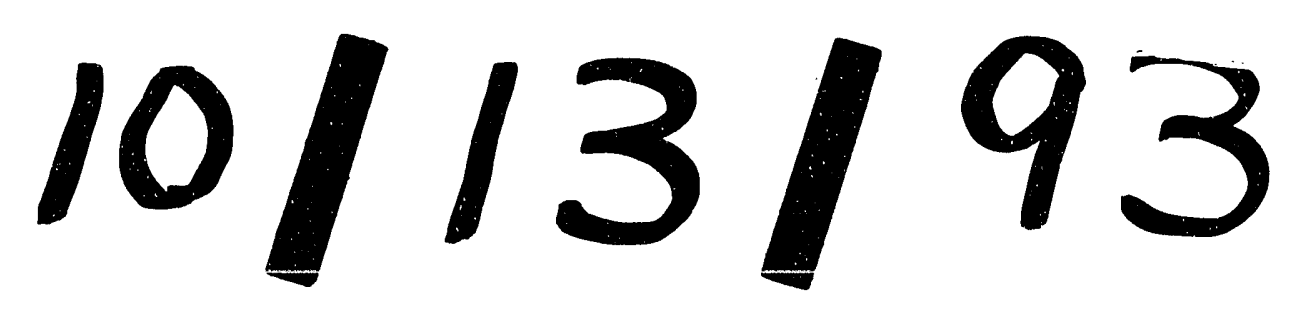


